\title{
Skillful prediction of winter Arctic Oscillation from previous summer in a linear empirical model
}

\author{
Hong-Li REN ${ }^{1,2,3^{*}} \& \mathrm{Yu} \mathrm{NIE}^{2}$ \\ ${ }^{1}$ State Key Laboratory of Severe Weather, Chinese Academy of Meteorological Sciences, Beijing 100081, China; \\ ${ }^{2}$ Laboratory for Climate Studies \& CMA-NJU Joint Laboratory for Climate Prediction Studies, National Climate Center, \\ China Meteorological Administration, Beijing 100081, China; \\ ${ }^{3}$ Department of Atmospheric Science, School of Environmental Studies, China University of Geoscience, Wuhan 430074, China
}

Received April 4, 2020; revised June 14, 2020; accepted July 21, 2020; published online October 26, 2020

\begin{abstract}
The winter Arctic Oscillation (WAO), as a primary atmospheric variability mode in the Northern Hemisphere, plays a key role in influencing mid-high-latitude climate variations. However, current dynamical seasonal forecasting systems have limited skills in predicting WAO with lead time longer than two months. In this study, we design a linear empirical model using two effective precursors from anomalies of the Arctic sea ice concentration (SIC) and the tropical sea surface temperature (SST) initiated in preceding late summer (August) which are both significantly correlated with WAO in recent four decades. This model can provide a skillful prediction of WAO at about half-year lead started from previous summer and perform much better than the dynamical models. Such a significantly prolonged lead time is owed to the stable precursor signals extracted from the SIC and SST anomalies over specific areas, which can persist from previous August and be further enhanced through autumn months. Validation results show that this model can produce a 20-year independent-validated prediction skill of 0.45 for $1999-2018$ and a 39-year cross-validated skill of 0.67 for 1980-2018, providing a potentially effective tool for earlier predictions of winter climate variations at mid-high latitudes.
\end{abstract}

Keywords Arctic Oscillation (AO), Winter AO prediction, Sea ice concentration, Sea surface temperature, Linear empirical model

Citation: Ren H, Nie Y. 2021. Skillful prediction of winter Arctic Oscillation from previous summer in a linear empirical model. Science China Earth Sciences, 64(1): 27-36, https://doi.org/10.1007/s11430-020-9665-3

\section{Introduction}

The winter Arctic Oscillation (denoted as WAO) has been well known as a primary atmospheric variability mode in the Northern Hemisphere (NH, Thompson and Wallace, 1998, 2000; Wallace, 2000) and plays a key role in affecting weather events and climate variations at mid-high latitudes (e.g., Thompson and Wallace, 2001; Zuo et al., 2015 and their review). Previous studies have focused on the features, mechanisms, and impacts of WAO in recent two decades. The WAO prediction, as the heart of mid-high-latitude pre-

* Corresponding author (email: renhl@cma.gov.cn) dictions, is of a great importance but a challenging issue to the operational weather forecast and climate prediction due to highly chaotic and stormy atmospheric activity (Cohen et al., 2002). However, the WAO prediction has been paid little attention in the past researches. This contrasts with its counterpart, the North Atlantic Oscillation (NAO), which got a substantial improvement in understanding its predictability and harvesting prediction skill based on statistical and dynamical models (cf., Wang et al., 2017 and references therein). This situation might be due to the much shorter research history of WAO ( 20 years) as compared with NAO ( $\sim 100$ years) in spite of an increased number of studies on the WAO-related dynamics (Walker and Bliss, 1932; Ambaum et 
al., 2001).

Previous studies showed statistically significant skill for WAO prediction based on atmospheric and coupled climate models, with a useful skill (superior to persistence forecast skill or with temporal correlation coefficient exceeding specific thresholds) at a lead up to 2 months (Derome et al., 2005; Riddle et al., 2013; Kang et al., 2014; Sun and Ahn, 2015; Kim and Ahn, 2015; Zuo et al., 2016) and slightly longer lead time by multi-model ensemble (MME) mean (L'Heureux et al., 2017). Some current operational seasonal forecasting systems have considerable skills in predicting WAO initiated in November-December but limited skill at a longer lead time than two months (e.g., MacLachlan et al., 2015; Ren et al., 2017), as also clearly shown in Figure 1. Although the spatial pattern of WAO can be reasonably reproduced by almost all of the CMIP3 and CMIP5 models, its magnitude, location and variability are simulated unsatisfactorily in these models (e.g., Miller et al., 2006; Zuo et al., 2013).

Variability of WAO has been considered to be primarily due to internal atmospheric dynamics and feedbacks, making a big challenge for its prediction beyond a few weeks (Feldstein, 2000; Robinson, 2000; Lorenz and Hartmann, 2003; Zhang et al., 2012). But some studies have suggested that a portion of the WAO variability may also be driven by external factors that operate on longer timescales, permitting some predictability of WAO at leads of one month or more. For example, WAO has linkages with the previous anomalies of the Arctic sea ice concentration (SIC) (Cohen et al., 2014; Yang et al., 2016) and tropical sea surface temperature (SST) (e.g., Greatbatch et al., 2003; Kang and Lee, 2017). Motivated from some previous research on the linear empirical models (LEMs) for predicting NAO and other climate phenomena (e.g., Wang et al., 2015; Wang et al., 2017; Ren et al., 2019), this study develops a LEM using effective precursors that can affect WAO from prior summer. The new LEM aims to make skillful WAO predictions at a prolonged lead time for performing better than the current operational dynamical models.

\section{Data and methods}

In this study, we use the 40-year (1979-2018) European Center for Medium-Range Weather Forecasts (ECMWF) Reanalysis-Interim data (ERA-Interim) for the $1.5^{\circ} \times 1.5^{\circ}$ latitude-longitude gridded atmospheric variables at constant pressure levels including monthly sea level pressure (SLP), surface air temperature, SST, and precipitation (Dee et al., 2011). Monthly SST from the Extended Reconstructed Sea Surface Temperature version 5 (ERSSTv5, Huang et al., 2017) and precipitation from the Global Precipitation Climatology Project (GPCP) dataset (Adler et al., 2003) are used to guarantee robustness of results. To analyze variability of the Arctic sea ice, the monthly $25 \mathrm{~km} \times 25 \mathrm{~km}$ polar stereographic gridded SIC dataset developed by the National Aeronautics and Space Administration (NASA) team is adopted (Cavalieri and Zwally, 1996). For illustrating prediction skill of current climate models, hindcast datasets of three operational coupled dynamical seasonal forecasting systems with a common period from 1983 to 2016 are used, viz. NCEP-CFSv2, ECMWF-System4, and BCC-CSM1.1m.

In this study, the boreal winter (January-March; JFM) is focused on as this period is often recognized as the WAO active season (Thompson and Wallace, 2000). The WAO spatial pattern is typically manifested by the seesaw between the Arctic and mid-latitude pressure anomalies and often defined as the first Empirical Orthogonal Function (EOF) of monthly SLP in the extratropical NH (Appendix Figure S1, https://link.springer.com). In this study, the WAO index are directly obtained from the Climate Prediction Center (CPC) website at https://www.cpc.ncep.noaa.gov/products/precip/ CWlink/daily_ao_index/ao.shtml. For prediction skill analysis of the dynamical models, the principal component (PC) based WAO index is employed. Specifically, the observational WAO index is calculated as the first PC of extratropical SLP. The model predicted WAO index is obtained by projecting the predicted monthly SLP anomalies onto the observed WAO patterns and normalized by the ensemble mean standard deviation for each model. This ensures the index represents the canonical AO. The prediction skill is then defined as the temporal correlation coefficient (TCC) between the predicted and observational WAO indices. The root mean square error (RMSE) is also used to validate the prediction skill results.

For the WAO prediction, we construct a LEM using the multi-variate linear regression technique (MLR). Both the take-one-year-out cross-validation and the 20-year forwardrolling independent validation (Ren et al., 2017) are used to validate the newly constructed LEM.

\section{Identifying predictors of WAO}

Figure 1 presents dynamical prediction skills of the JFMmean WAO indices in the three selected operational forecasting systems. The TCC skills generally feature a rapid decline with lead time increasing and become statistically insignificant at longer leads than two months when initiated in October and earlier. The RMSE on average shows increase with lead time for both NCEP-CFSv2A and BCC-CSM1.1m. There are not useful skills from the models initiated in summer (August) in spite of a somehow occasional skill recovery in September. These results clearly indicate limitation of current dynamical models on the long-lead prediction of WAO, though some models have significant 

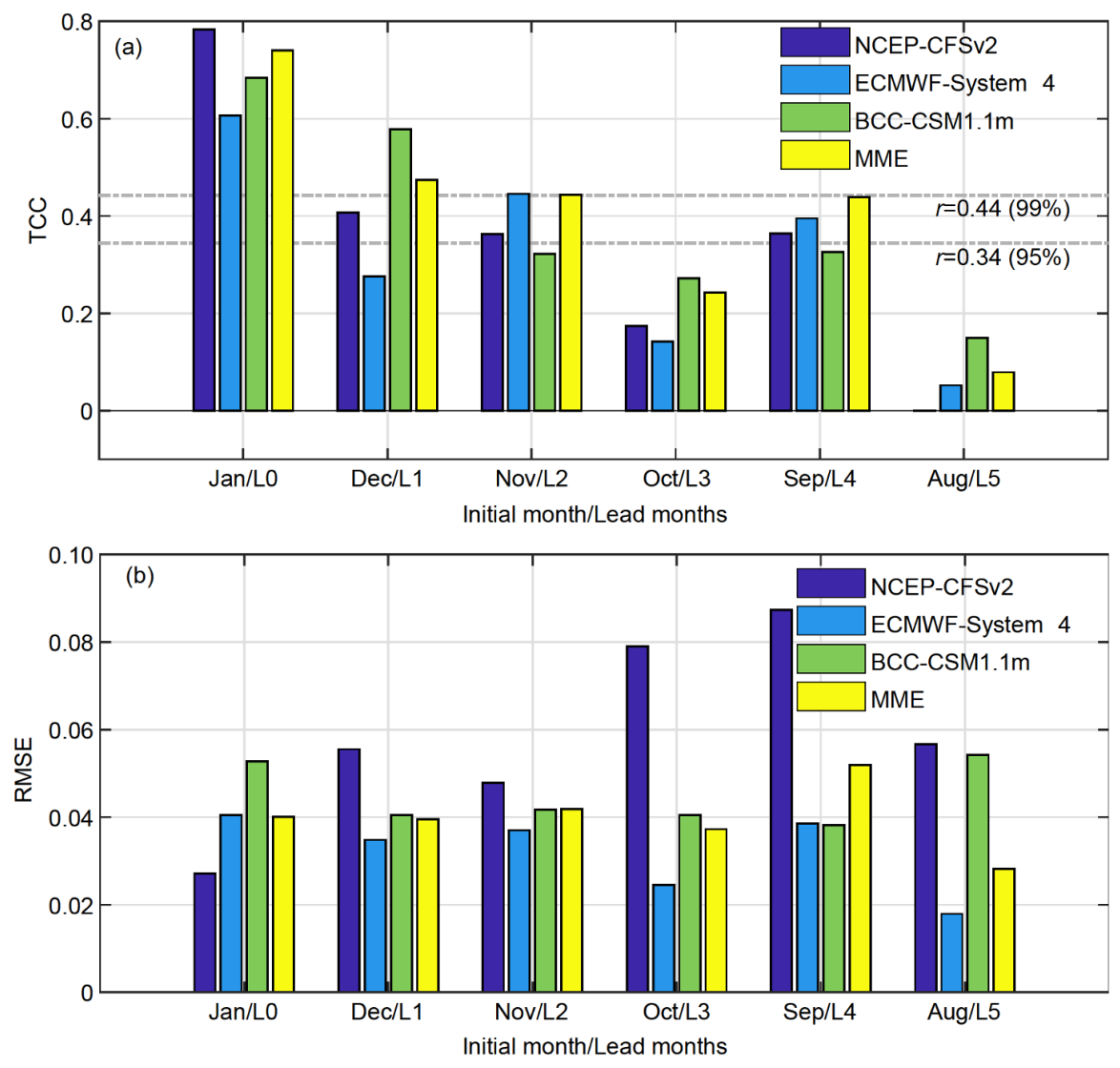

Figure 1 Skills of the WAO index predictions measured by (a) the temporal correlation coefficient and (b) the root mean square error as a function of initial months (Jan-Aug) which correspond to lead 0-5 months (L0-L5) by the NCEP-CFSv2, ECMWF-Systerm4, BCC-CSM1.1m, and their MME mean. The two gray dashed lines denote the TCC thresholds corresponding to the statistical Student $t$-test significance at the $95 \%$ and $99 \%$ confidence levels.

prediction skills at 1-2-month leads. The conclusion also holds for their multi-model ensemble mean that does not have the highest skill at most lead time.

Is it possible to skillfully predict WAO from previous summertime? An alternative way is to establish a LEM, which may overcome the limitation of the dynamical models in the WAO prediction at long leads. To build up such a LEM, the most important thing is to determine eligible predictors for predicting WAO based on our understanding of the physical processes that link potential precursors and WAO. Here, the two candidates, SIC and SST, are considered. It is well known that the SIC variability usually becomes stronger and more active from August to November and there is a quite good covariation between the autumn SIC variability and following winter circulation anomalies (Cohen et al., 2013; García-Serrano and Frankignoul, 2014; Barnes and Screen, 2015). Also, it is known that the tropical SST anomalies, partly associated with El Niño-South Oscillation (ENSO), may affect WAO (Dunstone et al., 2016; Yu and Lin, 2016; Dai and Tan, 2017; L'Heureux et al., 2017).

In Figure 2, the relationships between WAO and previous summer SIC/SST variations are identified through lagged correlation analysis. Note, the linear trend of SIC/SST anomalies has been removed before correlation analysis. As shown in Figure 2a, significant positive correlations between the August SIC anomalies and WAO index are found over the Barents-Kara Sea and Chukchi Sea, and negative correlations are over the East Siberian Sea. These significant correlations can persist well and be further enhanced from late summer through autumn months (Appendix Figure S2). This suggests that the SIC anomaly pattern in Figure 2a favors the positive phase of WAO in the following winter, implying that the August SIC could be a useful predictor for WAO. Based on this analysis, we can define an August SIC anomaly index $\left(\mathrm{SIC}_{\mathrm{Aug}}\right)$ as the SIC anomalies averaged over $\left(30^{\circ} \mathrm{E}-100^{\circ} \mathrm{E}, 75^{\circ} \mathrm{N}-85^{\circ} \mathrm{N}\right)$ and $\left(180^{\circ}-150^{\circ} \mathrm{W}, 70^{\circ} \mathrm{N}-80^{\circ} \mathrm{N}\right)$. The $\mathrm{SIC}_{\text {Aug }}$ has a good self-persistence for a few months (Appendix Figure S3) and significant correlations with the WAO index (Table 1), showing a good implication for predicting WAO.

We then identify the other precursor of WAO from tropical SST anomalies. As seen in Figure 2b, the WAO index has significant negative correlations with the August SST anomalies located over the tropical eastern Pacific which have a good persistence in the subsequent autumn (Appendix Figure S4). This indicates the negative SST anomalies over 
(a)

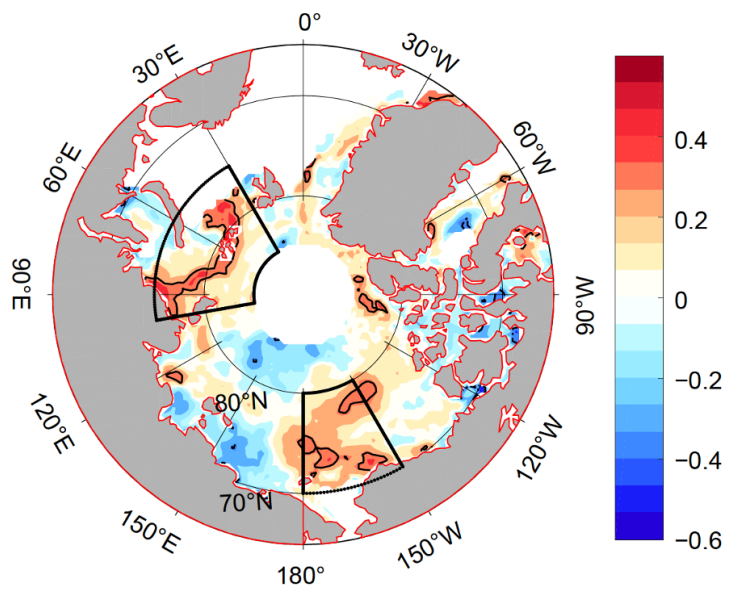

(b)
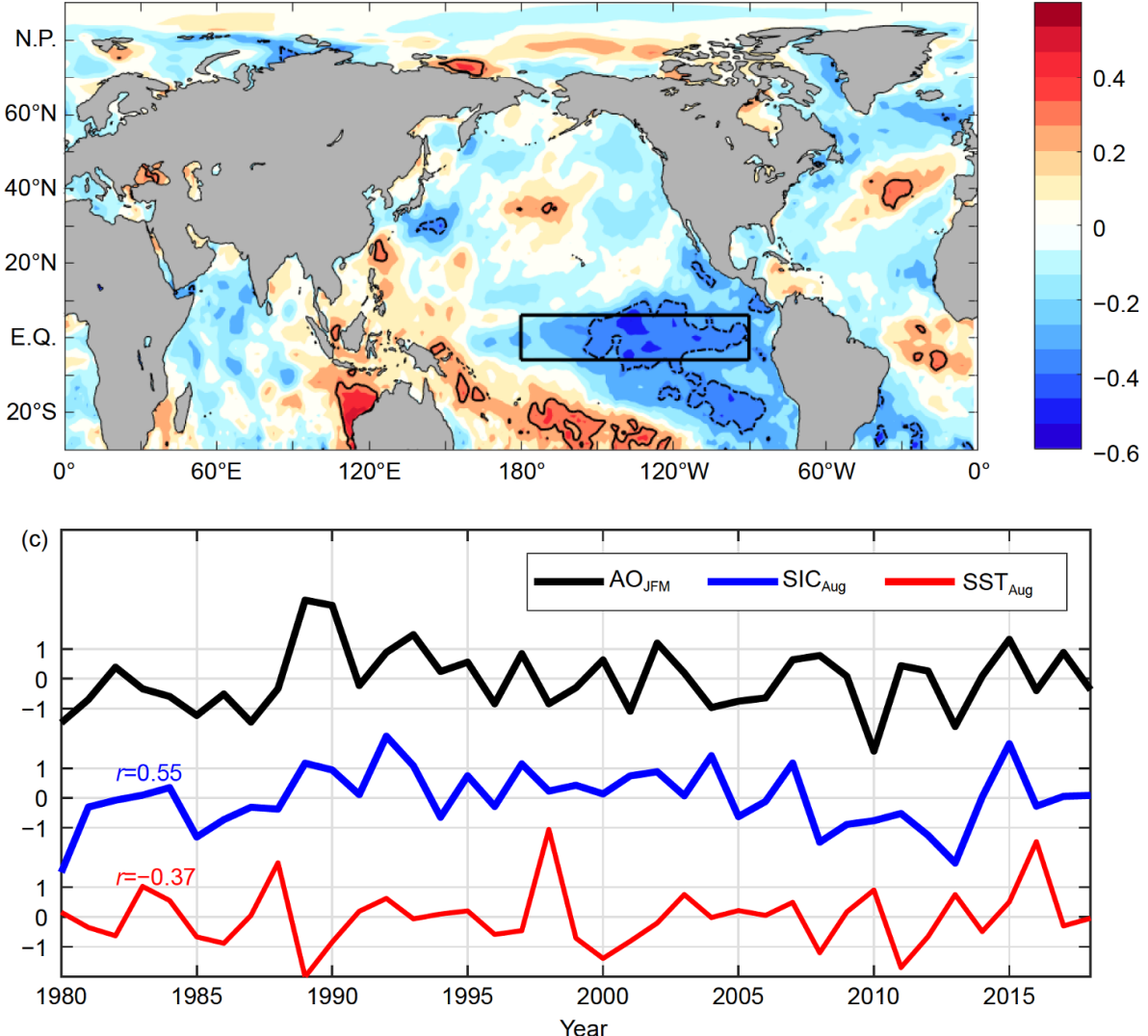

Figure 2 Correlations between the JFM-mean WAO index and the August anomalies of (a) SIC and (b) SST, respectively. The black-outlined boxes in denote key regions for (a) SIC and (b) SST indices. (c) Time series of the standardized JFM-mean WAO index and its two precursors in August, where the correlations between the precursors and WAO index are also given, and the black contours in (a) and (b) indicate the regions that are significant at the $95 \%$ confidence level.

Table 1 Correlations of the August predictors with the following monthly $\mathrm{AO}$ indices in winter ${ }^{\mathrm{a}}$

\begin{tabular}{lccccc}
\hline & Dec & Jan & Feb & Mar & JFM \\
\hline $\mathrm{R}\left(\mathrm{AO}, \mathrm{SIC}_{\text {Aug }}\right)$ & 0.14 & $\mathbf{0 . 4 6 * *}$ & $\mathbf{0 . 4 3 * *}$ & $\mathbf{0 . 3 6 *}$ & $\mathbf{0 . 5 5 * *}$ \\
$\mathrm{R}\left(\mathrm{AO}, \mathrm{SST}_{\text {Aug }}\right)$ & 0.05 & -0.21 & $-\mathbf{0 . 3 9 *}$ & -0.23 & $\mathbf{- 0 . 3 7 *}$ \\
\hline
\end{tabular}

a) Values with a statistical significance at the $95 \%$ and $99 \%$ confidence level of the Student's $t$-test are highlighted as bold with one and two asterisks, respectively. the traditional ENSO region correspond to the positive WAO phase. To quantify variation of the SST in this region, we define an August SST anomaly index ( $\mathrm{SST}_{\text {Aug }}$ ) as the SST anomalies averaged over $\left(180^{\circ}-90^{\circ} \mathrm{W}, 6^{\circ} \mathrm{S}-6^{\circ} \mathrm{N}\right)$. Significant correlations in Table 1 suggest that the August tropical eastern Pacific SST anomalies could be a good predictor for WAO. Moreover, significantly negative correlations appear in the Arctic ocean where the SIC has significant anomaly signals, implying a local intrinsic linkage between the SIC 
and SST anomalies. To further illustrate their relationships, the standardized indices of the WAO, $\mathrm{SIC}_{\text {Aug }}$ and $\mathrm{SST}_{\text {Aug }}$ are displayed in Figure 2c. The two predictor indices in August consistently fluctuate with the WAO index during the 39 years. The WAO index has a significant positive correlation $(0.55)$ with the $\mathrm{SIC}_{\text {Aug }}$ and a significant negative one $(-0.37)$ with the $\mathrm{SST}_{\mathrm{Aug}}$, indicating that the both predictors could bring predictability to the LEM.

Impacts of the summer SIC and SST anomalies on winter atmospheric circulation can be further revealed by examining correlations between the $\mathrm{SIC}_{\mathrm{Aug}} / \mathrm{SST}_{\mathrm{Aug}}$ indices and JFMmean SLP anomalies. As seen in Figure 3a, the correlation pattern of the SIC $_{\text {Aug }}$ with winter SLP shows negative values in the Arctic region and positive values in mid-latitude region, projecting onto the WAO pattern but with significant correlations in the Atlantic-Eurasian sector. Meanwhile, the correlation pattern between the $\mathrm{SST}_{\text {Aug }}$ and winter SLP shows positive values in the Arctic region and negative values at mid-latitudes, projecting onto the WAO pattern but with significant correlations in the Pacific-North Atlantic sector, as shown in Figure $3 \mathrm{~b}$. These two correlation patterns clearly suggest that the positive $\mathrm{SIC}_{\mathrm{Aug}}$ together with negative $\mathrm{SST}_{\text {Aug }}$ would favor the positive phase of WAO pattern by combining their individually complementary impact patterns in the Atlantic-Eurasian sector and the Pacific-North Atlantic sector.

The mechanisms through which the summer SIC/SST anomalies affecting WAO is generally discussed here. It has been previously revealed that the SIC anomaly over the Barents-Kara Sea in November could alter thermal structure of the lower troposphere, which then induce the meridional shift of the mid-latitude jet through either horizontal planetary wave propagation or the stratosphere-troposphere in- teraction, resulting in the AO-like atmospheric circulation anomaly (e.g., Wu and Smith, 2016; Yang et al., 2016). This is also confirmed here by the relatively high positive correlation between the WAO index and the November SIC anomalies which are initiated from August and persistently grow up through autumn (Appendix Figure S2). Therefore, the key is that the initial SIC signals occurred in August persist through autumn and further activate the feedback of sea ice onto atmosphere then affecting circulation anomalies which can project onto the WAO pattern in winter months (e. g., Dai et al., 2019) (Appendix Figure S5).

The ENSO-like SST anomalies in the tropical Pacific have long been believed to play an important role in affecting the mid-high-latitude winter climate including WAO through the Rossby wave propagation excited by tropical forcing (c.f., Butler et al., 2014; Scaife et al., 2017). Actually, the signals of August SST anomalies in the tropical Eastern Pacific can well persist into the early winter (Appendix Figure S4), which can further induce atmospheric heating/cooling that excites a specific extratropical teleconnection pattern through the Rossby wave train with one anomaly center in the Arctic and two other opposite-sign centers over the North Pacific and North Atlantic, respectively. Such a pattern can project onto the WAO-like circulation pattern during JFM, which is significantly visible in each month of JFM (Appendix Figure S6).

\section{Validations of the empirical prediction model}

We construct the LEM using the two complementary predictors (the $\mathrm{SIC}_{\text {Aug }}$ and $\mathrm{SST}_{\text {Aug }}$ ) which are weakly correlated with each other $(r=-0.006)$,

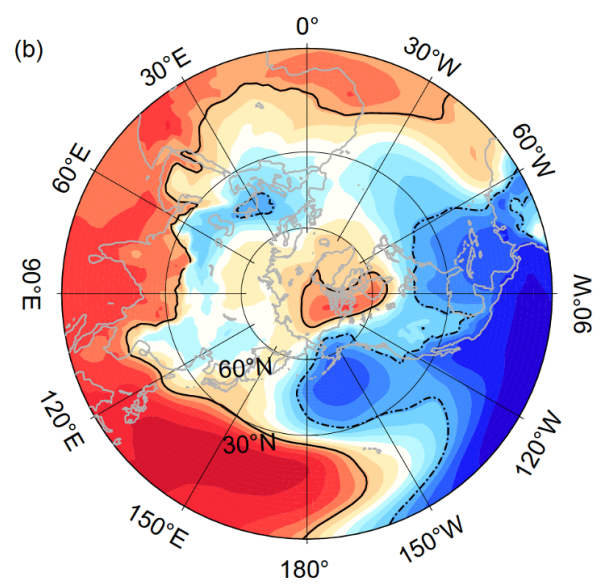

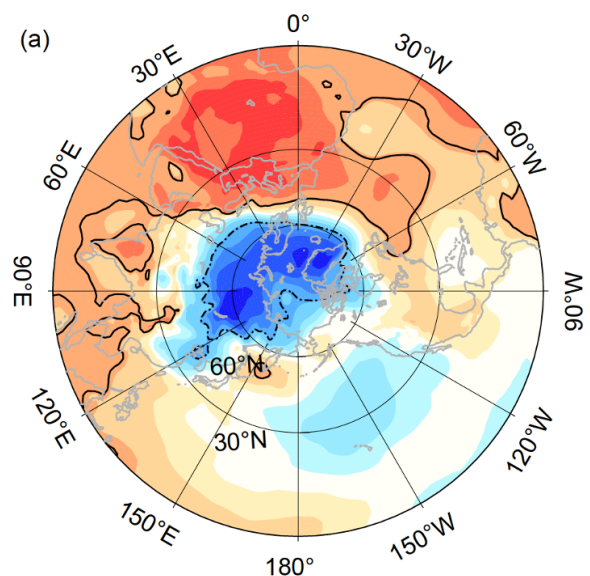

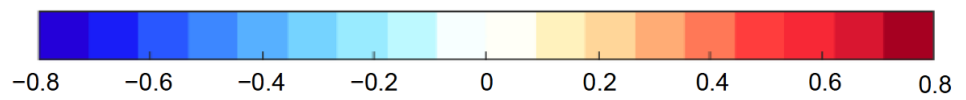

Figure 3 Correlation maps of the SIC (a) and SST (b) indices in August with the following JFM-mean SLP anomaly fields, respectively, where the black contours indicate the regions that are significant at the $95 \%$ confidence level. 
$\mathrm{AO}_{\mathrm{JFM}}=\beta_{0}+\beta_{1} \mathrm{SIC}_{\text {Aug }}+\beta_{2} \mathrm{SST}_{\text {Aug }}+\varepsilon$,

where $\beta_{0}, \beta_{1}, \beta_{2}$ are regression parameters to be estimated, and $\varepsilon$ represents noise.

Both of the predictors are physically linked with and significantly correlated to WAO using all the 39-year data (Table 1). To estimate the practical predictability of WAO, we further use the multi-variate linear regression (MLR) prediction equation to conduct both the take-one-year-out cross-validation and forward-rolling independent validation for the WAO prediction skill with the two selected predictors. For the take-one-year-out cross-validation, each time a 38-year segment is used to train the prediction model and then get the prediction of the remaining year. For the forward-rolling independent validation, we train the prediction model using the first $N$ years to get the prediction in the year of $N+1$. Here $N$ represents the number of sample years. The independent validation allows continually accumulated historical samples be more and more utilized into training the MLR equations which are expected to provide higher accuracy without any information after initial time used in prediction.

Figure 4 shows the validated predictions of the WAO index as compared with the observation. The hindcast time series is highly correlated with the observed one and their correlation skill reaches 0.67 . The predicted WAO index from the takeone-year-out cross validation is quite close to the observation with a significant correlation skill (0.6). For the independent validation, the LEM also presents a satisfactory performance and has a relative high prediction skill (0.45). Overall, such a LEM has a high capability of the WAO prediction though it misses some extreme WAO events, which is a common deficiency in empirical models. By quantifying the contributions of individual predictors (Wang et al., 2017), we found that the SIC anomaly index contributes more predictability to the prediction of WAO than the SST anomaly index. The percentage of WAO explained by the former reaches $30 \%$ while that explained by both of the predictors is about $45 \%$. As an independent predictor with a relatively lower contribution, the SST anomaly index still adds a supplementary skill to the WAO prediction, which have missed by the SIC index alone.

Since these LEMs can provide AO predictions up to 5 months, we next assess the prediction skills for the JFMmean AO index initialized from different months. Figure 5 shows WAO predictions at 1-5-month lead initialized from December, November, October, September, August, respectively. It is seen that the TCC scores stay at a stable but significant level for leads longer that two months, compared with those of the dynamical predictions as shown in Figure 1. The prediction skill is also confirmed by the RMSE results. Therefore, the LEM has a quite significant prediction skill in predicting the WAO index at almost half-year lead started from the previous summer. Note that the skills are not evi- dently increased with lead time shortened. It is presumably because the correlations between the WAO index and its two precursors become relatively weaker in November-December than prior months (Figures S2 and S4), whose mechanisms need further studies. One possibility is that planetary waves induced from active SIC anomalies propagate upward into the stratosphere before November and accumulated large-scale circulation anomalies propagate downwards into the troposphere making a WAO-like response in JFM (e.g., Cohen et al., 2014). Furthermore, the Chukchi sea ice variability becomes much weaker in November and December, but meanwhile, atmospheric variability is stronger there. Both of them may explain why the precursor in November-December does not have higher correlations with and prediction skills to WAO.

Given prominent impacts of WAO on climate variations at mid-high latitudes in the NH, the LEM can also be applied to the prediction of winter surface air temperature $\left(T_{2 \mathrm{~m}}\right)$ and precipitation at lead time longer than two months through using the model at each grid point. The predictions of $T_{2 \mathrm{~m}}$ and precipitation is computed via multiplying the predicted WAO index by the regression value of $T_{2 \mathrm{~m}}$ and precipitation onto the WAO index in observation. As seen in Figure 6, prediction skills of the hindcast and cross validation are significantly high for surface air temperature over the Eurasian and eastern North American areas, and for precipitation with a much-reduced area over the high-latitude Eurasia. All these areas are where WAO prominently impacts (Thompson and Wallace, 2001). Therefore, the LEM is capable to provide skillful predictions of winter surface climate over many areas of the extratropical NH at lead up to previous August. Indeed, more precursors will be needed to further improve these prediction skills.

\section{Summary and discussions}

The WAO prediction is at the heart of the mid-high-latitude climate prediction but usually loses its skills quickly in the dynamical seasonal forecasting systems with lead time longer than two months. Here, we show that the summer Arctic SIC anomalies contribute primarily to the predictability of WAO through sea ice-atmosphere interactions. The tropical Pacific SST anomalies contribute secondarily to the predictability through a tropic-Arctic teleconnection. Together, the two predictors make the possibility that WAO can be skillfully predicted with lead times longer than two months, even up to half a year. Therefore, the LEM for predicting the WAO index has been built up based on these two primary predictors initiated from previous August through sequent autumn. Validation results showed that this model can produce a 20 -year independent-validated prediction skill of 0.45 for 1999-2018 and a 39-year cross-vali- 

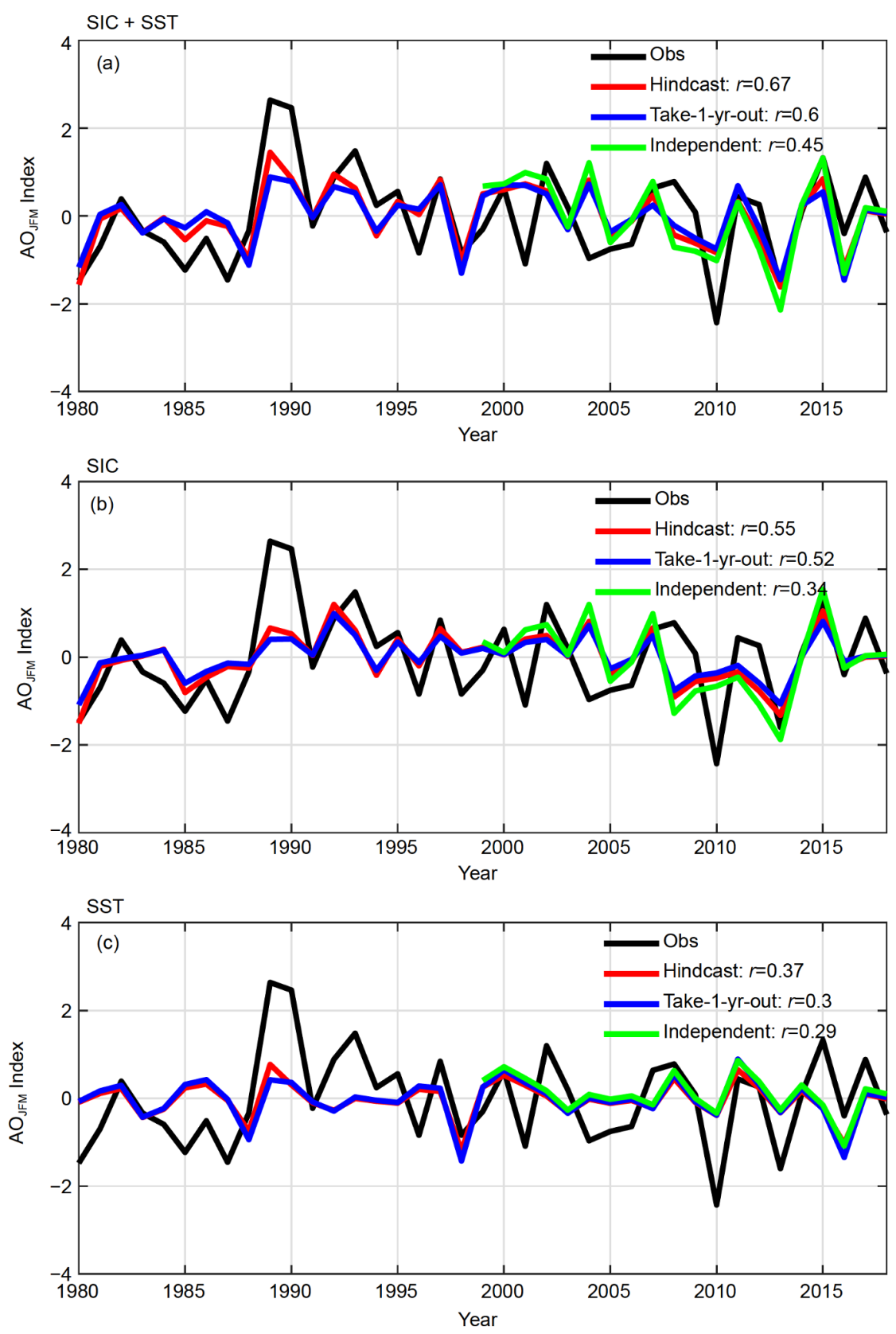

Figure 4 The JFM-mean WAO indices of observation and predictions based on the LEMs with the different combinations of the August precursors: (a) SIC +SST, (b) SIC only, and (c) SST only. Note, for the 1-year-taken-out cross-validation, the WAO index is recalculated based on the training period following the method in the CPC website (https://www.cpc.ncep.noaa.gov/products/precip/CWlink/daily_ao_index/ao.shtml.).

dated skill of 0.67 for $1980-2018$. This study provides an effective tool for better predicting WAO and its impacted winter climate variations at mid-high latitudes.

Although as suggested by previous studies, several dynamical seasonal forecasting systems have exhibited valuable prediction skills (higher than the persistence prediction based on observation) (Riddle et al., 2013; Kang et al., 2014; Sun and Ahn, 2015), their prediction skills are limited within two months. The main reason may presumably be due to the limited performance of the current climate system models in representing complex interactions between the polar sea ice and atmospheric circulation. It is also a possibility that the teleconnections and remote effects of the tropical forcing on the Arctic atmospheric variations are not yet well represented in current prediction models. Both of the two aspects need to be studied further.

Moreover, detailed physical mechanisms how the Arctic SIC and tropical Pacific SST anomalies can influence a delayed WAO variability still remain as an open question. Such long-lead relationships were also suggested by Dunstone et al. (2016) who, based on multivariate regression/ correlation analyses, showed that ENSO and stratospheric 

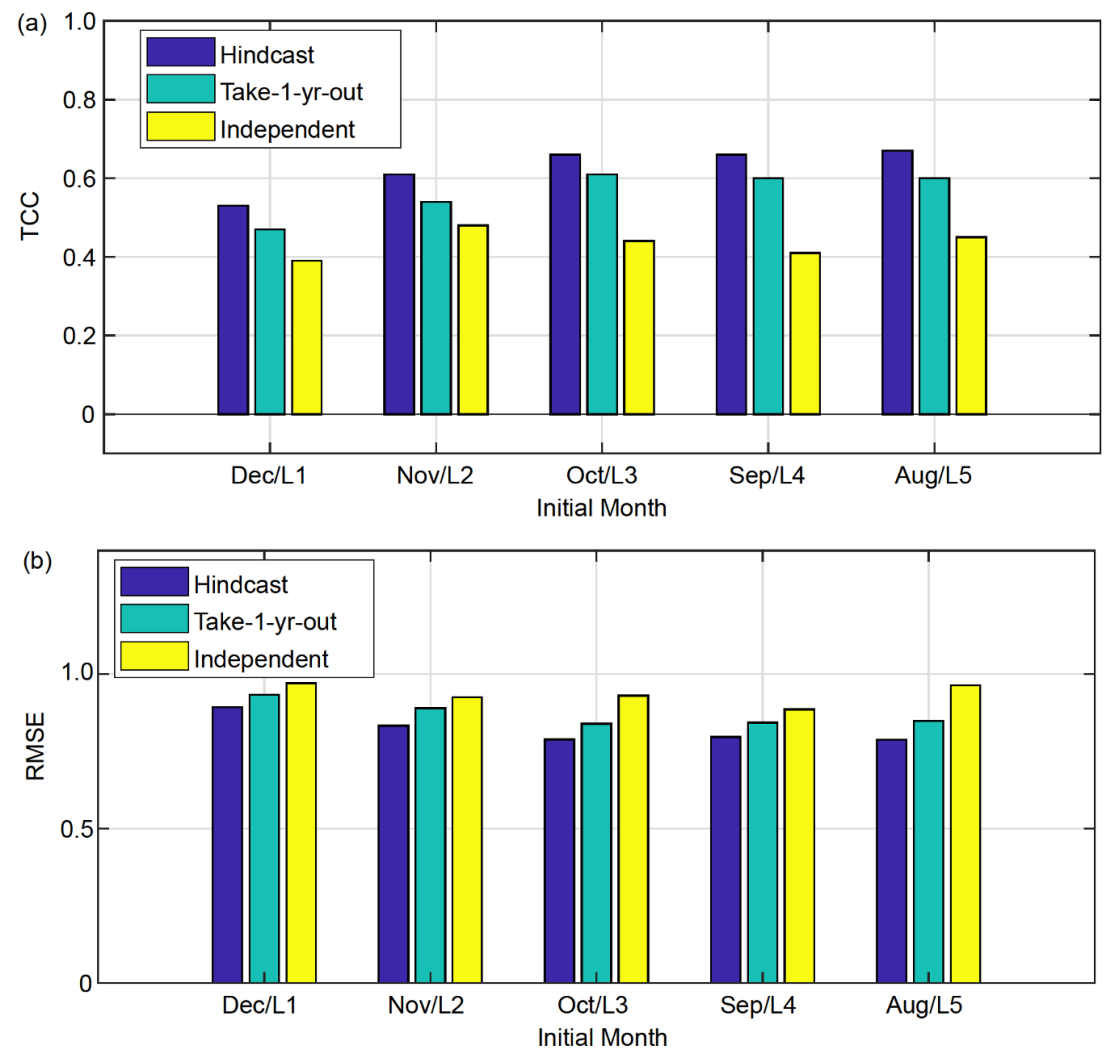

Figure 5 Prediction skills of the JFM-mean WAO index measured by (a) the temporal correlation coefficient and (b) the root mean square error initiated from December to August based on the LEMs using both the SIC and SST precursors.
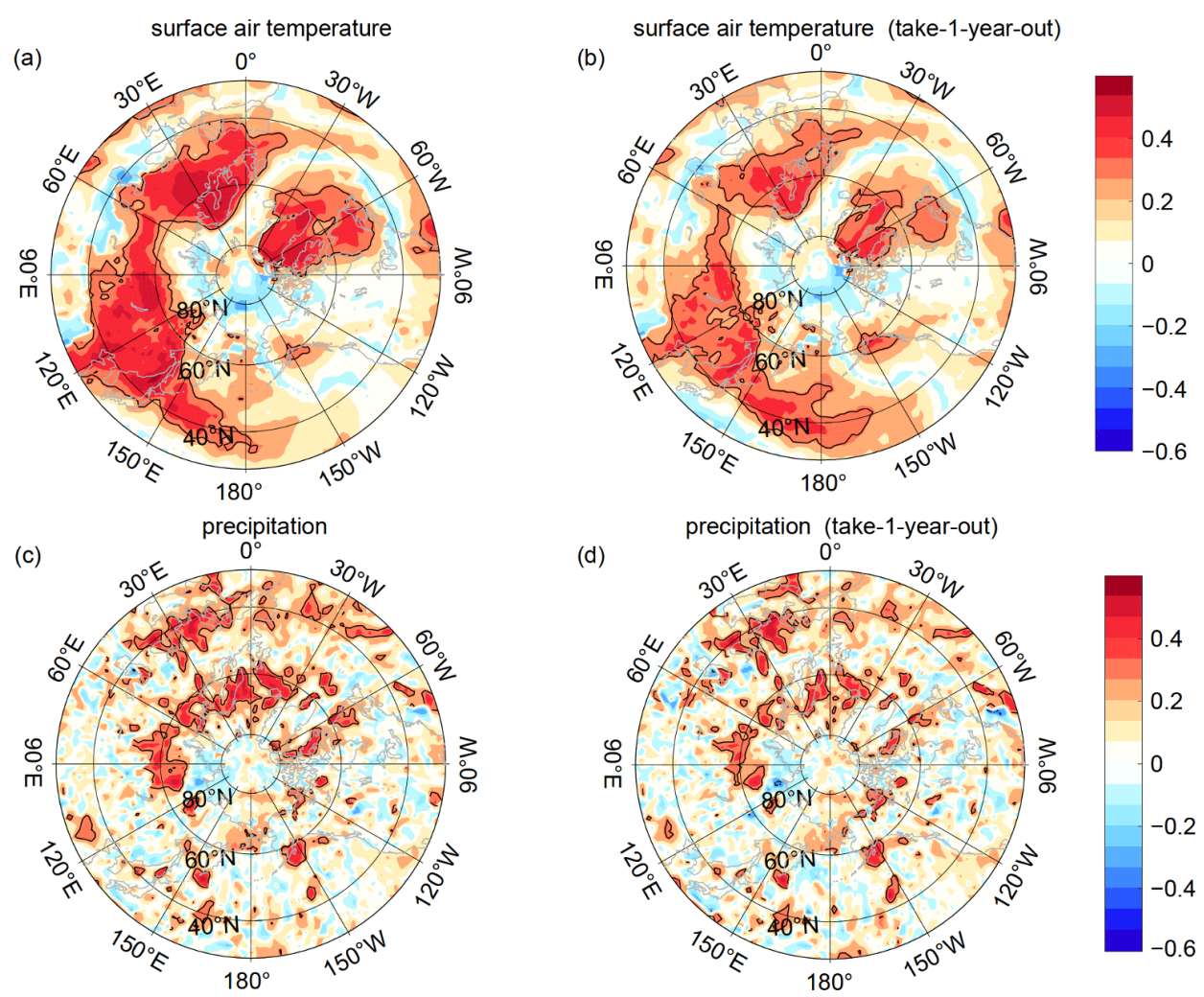

Figure 6 Prediction TCC skills of the winter JFM-mean (a) surface air temperature and (c) precipitation for hindcast initiated from August. (b) and (d) are same as in (a), (c) but for the prediction skill with one year taken out. The black contours indicate the regions that are significant at the $95 \%$ confidence level. 
polar vortex can account for the winter NAO skill up to $\sim 13$ months. However, the physical processes through which these first winter predictors affecting the second winter NAO still lack understanding. The effectiveness of our LEM may help explore the mechanisms on how the following summer boundary condition affects the second winter NAO or WAO.

Acknowledgements The authors thank the three anonymous reviewers for their constructive suggestions, which help improve the quality of the manuscript. This work was supported by the China National Key Research and Development Program on Monitoring, Early Warning and Prevention of Major Natural Disaster (Grant No. 2018YFC1506005), and the National Natural Science Foundation of China (Grant Nos. 41705043, 41775066 \& 41375062).

Open Access This article is licensed under a Creative Commons Attribution 4.0 International License, which permits use, sharing, adaptation, distribution and reproduction in any medium or format, as long as you give appropriate credit to the original author(s) and the source, provide a link to the Creative Commons licence, and indicate if changes were made. The images or other third party material in this article are included in the article's Creative Commons licence, unless indicated otherwise in a credit line to the material. If material is not included in the article's Creative Commons licence and your intended use is not permitted by statutory regulation or exceeds the permitted use, you will need to obtain permission directly from the copyright holder. To view a copy of this licence, visit http://creativecommons.org/licenses/by/4.0/.

\section{References}

Adler R F, Huffman G J, Chang A, Ferraro R, Xie P P, Janowiak J, Rudolf B, Schneider U, Curtis S, Bolvin D, Gruber A, Susskind J, Arkin P, Nelkin E. 2003. The version-2 global precipitation climatology project (GPCP) monthly precipitation analysis (1979-present). J Hydrometeorol, 4: 1147-1167

Ambaum M H P, Hoskins B J, Stephenson D B. 2001. Arctic Oscillation or North Atlantic Oscillation? J Clim, 14: 3495-3507

Barnes E A, Screen J A. 2015. The impact of arctic warming on the midlatitude jet-stream: Can it? Has it? Will it? WIREs Clim Change, 6: 277-286

Butler A H, Polvani L M, Deser C. 2014. Separating the stratospheric and tropospheric pathways of El Niño-Southern Oscillation teleconnections. Environ Res Lett, 9: 024014

Cavalieri D J, Parkinson C L, Gloersen P, Zwally H J. 1996. Updated yearly. Sea Ice Concentrations from Nimbus-7 SMMR and DMSP SSM/I-SSMIS Passive Microwave Data, Version 1. Boulder, Colorado USA. NASA National Snow and Ice Data Center Distributed Active Archive Center. doi: 10.5067/8GQ8LZQ

Cohen J, Salstein D, Saito K. 2002. A dynamical framework to understand and predict the major Northern Hemisphere mode. Geophys Res Lett, 29: $51-1-51-4$

Cohen J, Jones J, Furtado J, Tziperman E. 2013. Warm arctic, cold continents: A common pattern related to arctic sea ice melt, snow advance, and extreme winter weather. Oceanography, 26: 150-160

Cohen J, Screen J A, Furtado J C, Barlow M, Whittleston D, Coumou D, Francis J, Dethloff K, Entekhabi D, Overland J, Jones J. 2014. Recent Arctic amplification and extreme mid-latitude weather. Nat Geosci, 7: $627-637$

Dai P, Tan B. 2017. The nature of the Arctic Oscillation and diversity of the extreme surface weather anomalies it generates. J Clim, 30: 5563-5584

Dai A, Luo D, Song M, Liu J. 2019. Arctic amplification is caused by seaice loss under increasing $\mathrm{CO}_{2}$. Nat Commun, 10: 121

Dee D P, Uppala S M, Simmons A J, Berrisford P, Poli P, Kobayashi S,
Andrae U, Balmaseda M A, Balsamo G, Bauer P, Bechtold P, Beljaars A C M, van de Berg L, Bidlot J, Bormann N, Delsol C, Dragani R, Fuentes M, Geer A J, Haimberger L, Healy S B, Hersbach H, Hólm E V, Isaksen L, Kållberg P, Köhler M, Matricardi M, McNally A P, Monge-Sanz B M, Morcrette J J, Park B K, Peubey C, de Rosnay P, Tavolato C, Thépaut J N, Vitart F. 2011. The ERA-interim reanalysis: Configuration and performance of the data assimilation system. Q J R Meteorol Soc, 137: 553-597

Derome J, Lin H, Brunet G. 2005. Seasonal forecasting with a simple general circulation model: Predictive skill in the AO and PNA. J Clim, 18: 597-609

Dunstone N, Smith D, Scaife A, Hermanson L, Eade R, Robinson N, Andrews M, Knight J. 2016. Skilful predictions of the winter North Atlantic Oscillation one year ahead. Nat Geosci, 9: 809-814

Feldstein S B. 2000. The timescale, power spectra, and climate noise properties of teleconnection patterns. J Clim, 13: 4430-4440

García-Serrano J, Frankignoul C. 2014. High predictability of the winter Euro-Atlantic climate from cryospheric variability. Nat Geosci, 7: E1

Greatbatch R J, Lin H, Lu J, Peterson K A, Derome J. 2003. Tropical/ extratropical forcing of the AO/NAO: A corrigendum. Geophys Res Lett, 30: 1738

Huang B, Thorne P W, Banzon V F, Boyer T, Chepurin G, Lawrimore J H, Menne M J, Smith T M, Vose R S, Zhang H M. 2017. Extended Reconstructed Sea Surface Temperature, Version 5 (ERSSTv5): Upgrades, validations, and intercomparisons. J Clim, 30: 8179-8205

Kang D, Lee M I. 2017. Increase in the potential predictability of the Arctic Oscillation via intensified teleconnection with ENSO after the mid1990s. Clim Dyn, 49: 2147-2160

Kang D, Lee M I, Im J, Kim D, Kim H M, Kang H S, Schubert S D, Arribas A, MacLachlan C. 2014. Prediction of the Arctic Oscillation in boreal winter by dynamical seasonal forecasting systems. Geophys Res Lett, 41: 3577-3585

Kim H J, Ahn J B. 2015. Improvement in prediction of the Arctic Oscillation with a realistic ocean initial condition in a CGCM. J Clim, 28: 8951-8967

L'Heureux M L, Tippett M K, Kumar A, Butler A H, Ciasto L M, Ding Q, Harnos K J, Johnson N C. 2017. Strong relations between ENSO and the Arctic Oscillation in the North American multimodel ensemble. Geophys Res Lett, 44: 11,654

Lorenz D J, Hartmann D L. 2003. Eddy-zonal flow feedback in the Northern hemisphere winter. J Clim, 16: 1212-1227

Miller R L, Schmidt G A, Shindell D T. 2006. Forced annular variations in the 20th century Intergovernmental Panel on Climate Change Fourth Assessment Report models. J Geophys Res, 111: D18101

MacLachlan C, Arribas A, Peterson K A, Maidens A, Fereday D, Scaife A A, Gordon M, Vellinga M, Williams A, Comer R E, Camp J, Xavier P, Madec G. 2015. Global Seasonal forecast system version 5 (GloSea5): A high-resolution seasonal forecast system. Q J R Meteorol Soc, 141: 1072-1084

Riddle E E, Butler A H, Furtado J C, Cohen J L, Kumar A. 2013. CFSv2 ensemble prediction of the wintertime Arctic Oscillation. Clim Dyn, 41: 1099-1116

Ren H L, Jin F F, Song L, Lu B, Tian B, Zuo J, Liu Y, Wu J, Zhao C, Nie Y, Zhang P, Ba J, Wu Y, Wan J, Yan Y, Zhou F. 2017. Prediction of primary climate variability modes at the Beijing Climate Center. J Meteorol Res, 31: 204-223

Ren H L, Zuo J, Deng Y. 2019. Statistical predictability of Niño indices for two types of ENSO. Clim Dyn, 52: 5361-5382

Robinson W A. 2000. A baroclinic mechanism for the eddy feedback on the zonal index. J Atmos Sci, 57: 415-422

Scaife A A, Comer R E, Dunstone N J, Knight J R, Smith D M, MacLachlan C, Martin N, Peterson K A, Rowlands D, Carroll E B, Belcher S, Slingo J. 2017. Tropical rainfall, Rossby waves and regional winter climate predictions. Q J R Meteorol Soc, 143: 1-11

Sun J, Ahn J B. 2015. Dynamical seasonal predictability of the Arctic Oscillation using a CGCM. Int J Climatol, 35: 1342-1353

Thompson D W J, Wallace J M. 1998. The Arctic oscillation signature in 
the wintertime geopotential height and temperature fields. Geophys Res Lett, 25: 1297-1300

Thompson D W J, Wallace J M. 2000. Annular modes in the extratropical circulation. Part I: Month-to-month variability. J Clim, 13: 1000-1016

Thompson D W J, Wallace J M. 2001. Regional climate impacts of the Northern Hemisphere annular mode. Science, 293: 85-89

Walker G T, Bliss E W. 1932. World weather V. Mem Roy Meteor Soc, 4: 53-84

Wallace J M. 2000. North atlantic oscillatiodannular mode: Two paradigms-one phenomenon. Q J R Meteorol Soc, 126: 791-805

Wang B, Xiang B, Li J, Webster P J, Rajeevan M N, Liu J, Ha K J. 2015. Rethinking Indian monsoon rainfall prediction in the context of recent global warming. Nat Commun, 6: 7154

Wang L, Ting M, Kushner P J. 2017. A robust empirical seasonal prediction of winter NAO and surface climate. Sci Rep, 7: 279

Wu Y, Smith K L. 2016. Response of Northern hemisphere midlatitude circulation to Arctic amplification in a simple atmospheric general circulation model. J Clim, 29: 2041-2058

Yang X Y, Yuan X, Ting M. 2016. Dynamical link between the BarentsKara Sea Ice and the Arctic Oscillation. J Clim, 29: 5103-5122

Yu B, Lin H. 2016. Tropical atmospheric forcing of the wintertime North Atlantic oscillation. J Clim, 29: 1755-1772

Zhang Y, Yang X Q, Nie Y, Chen G. 2012. Annular mode-like variation in a multilayer quasigeostrophic model. J Atmos Sci, 69: 2940-2958

Zuo J Q, Li W J, Ren H L. 2013. Representation of the Arctic Oscillation in the CMIP5 models. Adv Clim Change Res, 4: 242-249

Zuo J, Ren H L, Li W. 2015. Contrasting impacts of the Arctic Oscillation on surface air temperature anomalies in Southern China between early and middle-to-late winter. J Clim, 28: 4015-4026

Zuo J, Ren H L, Wu J, Nie Y, Li Q. 2016. Subseasonal variability and predictability of the Arctic Oscillation/North Atlantic Oscillation in BCC_AGCM2.2. Dyn Atmos Oceans, 75: 33-45 